\title{
Spatial and temporal changes in Lutzomyia longipalpis abundance, a Leishmania infantum vector in an urban area in northeastern Argentina
}

\author{
María Soledad Fernández ${ }^{1,2} /{ }^{+}$, María Soledad Santini' ${ }^{1}$ Regino Cavia ${ }^{2,3}$, Adolfo Enrique Sandoval ${ }^{4}$, \\ Adriana Alicia Pérez ${ }^{3}$, Soraya Acardi ${ }^{5}$, Oscar Daniel Salomón²,6 \\ ${ }^{1}$ Centro Nacional de Diagnóstico e Investigación en Endemo-Epidemias, Buenos Aires, Argentina \\ ${ }^{2}$ Consejo Nacional de Investigaciones Científicas y Técnicas, Buenos Aires, Argentina \\ ${ }^{3}$ Facultad de Ciencias Exactas y Naturales, Universidad de Buenos Aires, Buenos Aires, Argentina \\ ${ }^{4}$ Laboratorio de Control de Vectores, Secretaría de Calidad de Vida de la Municipalidad de Posadas, Posadas, \\ Misiones, Argentina ${ }^{5}$ Laboratorio de Biología Molecular Aplicada, Facultad de Ciencias Exactas, Químicas y Naturales, \\ Universidad Nacional de Misiones, Misiones, Argentina ${ }^{6}$ Instituto Nacional de Medicina Tropical, Puerto Iguazú, Misiones, Argentina
}

This study aimed to analyse changes in the spatial distribution of Lutzomyia longipalpis in Posadas, an urban area located in northeastern Argentina. Data were obtained during the summer of 2007 and 2009 through two entomological surveys of peridomiciles distributed around the city. The abundance distribution pattern for 2009 was computed and compared with the previous pattern obtained in 2007, when the first human visceral leishmaniasis cases were reported in the city. Vector abundance was also examined in relation to micro and macrohabitat characteristics. In 2007 and 2009, Lu. longipalpis was distributed among 41.5\% and 31\% of the households in the study area, respectively. In both years, the abundance rates at most of the trapping sites were below $30 \mathrm{Lu}$. longipalpis per trap per night; however, for areas exhibiting 30-60 Lu. longipalpis and more than $60 \mathrm{Lu}$. longipalpis, the areas increased in both size and number from 2007-2009. Lu. longipalpis was more abundant in areas with a higher tree and bush cover (a macrohabitat characteristic) and in peridomiciles with accumulated unused material (a microhabitat characteristic). These results will help to prioritise and focus control efforts by defining which peridomiciles display a potentially high abundance of $\mathrm{Lu}$. longipalpis.

Key words: Lutzomyia longipalpis - visceral leishmaniasis - urban environment

In Latin America, Lutzomyia longipalpis is the main vector of Leishmania infantum (syn. Leishmania chagasi), the causal agent of visceral leishmaniasis (VL) (Lainson \& Rangel 2005). This illness has been described as a rural disease. However, urban outbreaks have been the recent trend, with the domestic dog serving as the main urban reservoir (Ready 2008). Lu. longipalpis is highly adaptable to peri-urban and urban settings (Harhay et al. 2011) and previous studies of the region have shown that $L u$. longipalpis is abundant in areas that are densely populated with humans (Fernández et al. 2010, Harhay et al. 2011).

The historical transmission pattern of VL indicates that the parasite circulates in rural forested areas or even at the periphery of urban environments (Feliciangeli et al. 2006). VL transmission has also been observed in middle-class neighbourhoods in highly urbanised areas (Cerbino Neto et al. 2009).

doi: $10.1590 / 0074-0276130047$

ODS and RC are researchers of CONICET-Argentina, MSF has a

fellowship from CONICET.

+ Corresponding author: sfernandez79@gmail.com

Received 25 January 2013

Accepted 6 August 2013
Some environmental characteristics, such as the presence of chickens and other domestic animals, fruit trees and deficient sanitary conditions, may increase the abundance of sandflies by providing suitable breeding sites (Sherlock 1996, Alexander et al. 2002, Oliveira et al. 2003, 2006, Costa et al. 2005, Fernández et al. 2010).

During the summer of 2007, four autochthonous human VL cases were recorded for the first time in Argentina, in the city of Posadas (province of Misiones), together with the presence of $\mathrm{Lu}$. longipalpis and infected dogs (Salomón et al. 2008). From the end of 20062009, the incidence of human cases of VL in Posadas increased to 32 (National Health Surveillance, Health Ministry). However, a study conducted in this urban area of Argentina showed that the distribution of Lu. longipalpis throughout Posadas was not uniform; this vector was distributed in areas of high abundance surrounded by areas of low abundance (Fernández et al. 2010). The environmental characteristics of areas with a high vector abundance were associated with socio-economic variables that encouraged the presence of the vector within densely populated areas. These characteristics included a high proportion of tree and bush cover, the presence of chickens, an absence of electrical power and a low proportion of houses with lack of building materials and economic deprivation. This last socio-environmental variable indicates that the areas of high vector abundance are mainly found within the urban environment, rather 
than in the ruralised peri-urban environment (Fernández et al. 2010). In another study conducted in Posadas, Santini et al. (2012) found that patches of high vector abundance were associated with a large number of plant pots and trees and less ground cover by land or grass.

Salomón and Quintana (2011) described three spatial scales of analysis for studying vector abundance and the incidence of human cases: microscale, mesoscale and macroscale. The first scale refers to changes in vegetation on a small scale, such as housing and peridomicile characteristics. The second scale refers to the effects of deforestation and urbanisation at a local level, where a metapopulation structure of vectors and/or outbreakrelated phenomena can be found. The third scale refers to the distribution of large-scale trends (country) and the potential distribution of species in eco-regions.

Within a microscale framework, we can examine the response of vector abundance to environmental variables recorded at micro and macrohabitat levels. We can define macrohabitats as distinguishable units where an individual performs all of its biological functions during a typical activity cycle. A microhabitat can be characterised by the physical and chemical variables that influence the location of an individual within its macrohabitat (Morris 1987). In the present study, we defined macrohabitat characteristics as those that describe a neighbourhood and microhabitat characteristics as those that describe households. In a previous study in Posadas, most of the environmental variables used to explain the abundance distribution of Lu. longipalpis were surveyed at the census-tract level, which corresponds to neighbourhoods, while little information about the sampled households was recorded (Fernández et al. 2010).

The aim of this study was to analyse the changes in the spatial distribution of Lu. longipalpis in Posadas during an early stage of an outbreak and two years later, in 2007 and 2009, respectively, and to examine the association between vector abundance and micro and macrohabitat characteristics.

\section{MATERIALS AND METHODS}

Study area - Posadas is located on the northeastern border of Argentina $\left(27^{\circ} 23^{\prime} \mathrm{S} 55^{\circ} 53^{\prime} \mathrm{W}, 120 \mathrm{~m}\right.$ above sea level) and is the most populated city of Misiones, with more than 320,000 inhabitants (National Institute of Statistics and Census 2010) (indec.com.ar). The city is located on the shore of the Paraná River in the Paranaense forest eco-region, a subtropical humid forest of the Amazonian domain. The mean annual temperature and precipitation in the area are $22.2^{\circ} \mathrm{C}$ and $1,699 \mathrm{~mm}$, respectively (National Institute of Statistics and Census 2009).

Entomological data - Lu. longipalpis captures were performed in 2007 and 2009 between January-March (2007: from 1 February-31 March; 2009: from 21 January-11 March). This period displays a high abundance of Phlebotominae, which occurs during the warmest temperatures after the rainy season (Oliveira et al. 2008, Fernández et al. 2012). In both surveys, the city was divided into a grid of $400 \mathrm{~m} \times 400 \mathrm{~m}$. In each case, the "worst scenario" method was used to select at least one household within the area (Feliciangeli et al. 2006, Antonialli et al. 2007). Worst scenarios are characterised by the presence of vegetation, which provides shadow, moist soil, detritus, access to blood sources and a lack of light interference. A CDC battery-operated mini-light trap was placed in the household peridomicile overnight. Although the sampled areas were the same in 2007 and 2009, not all of the sampled households were the same. All of the sampled households were geopositioned with a GPS and located within a map of Posadas using ArcView GIS 3.2a 1999 (Environmental Systems Research Institute, ArcView Spatial Analyst 2.0a, New York, USA). A total of 282 and 310 households from the same spatial area were sampled in 2007 and 2009, respectively, and included in the comparative analysis. Each household was sampled for only one night, though exceptions were made when Phlebotominae were not captured in any of the traps or when unfavourable weather conditions were recorded (rain, strong winds) that would prevent the presence of sandflies. In such cases, the first night was discarded during the analysis to avoid any biases and to rule out possible negative values for vector abundance. To maintain proper storage of the Phlebotominae, the captured specimens were kept at $-20^{\circ} \mathrm{C}$. They were treated with lacto-phenol, observed with an optical microscope and identified according to Galati's key (2003), using generic abbreviations according to Marcondes (2007). During the sampling period, the $L u$. longipalpis abundance at each household was estimated using the number of specimens captured per trap-night. The observed Lu. longipalpis abundances were compared between the two years using a generalised linear model, with a Poisson distribution for errors and a logarithm link function. To account for overdispersion, the standard errors (SE) were corrected using a quasi-Poisson model (McCullagh \& Nelder 1989). We also compared the proportion of positive households between the two years using a proportion Z-test.

Although both of the surveys were conducted during the summer, the daily maximum and minimum temperatures and the daily maximum wind speeds were compared for the sampling periods ( $t$ test, alpha with a Bonferroni correction of 0.01 , meteorological data available from Posadas airport, provided by the National Weather Service).

Spatial analysis - The semivariogram function was computed for the $\mathrm{Lu}$. longipalpis abundance values obtained in 2009 to compare the spatial dependence of vector abundance between the two years. To estimate the range, the nugget and the sill, we fitted the semivariogram function using a spherical model. To account for anisotropy, four directions were considered: $0^{\circ}, 45^{\circ}, 90^{\circ}$ and $135^{\circ}$. Vector abundance was interpolated using an ordinary kriging procedure to locate patches and gaps of abundance in the city and to compare the changes in the spatial pattern. These analyses were performed using S-PLUS 6.0 with a spatial extension module (Insightful 2001).

The interpolated abundance was categorised into three levels: low abundance (less than 30 individuals per trap-night), intermediate abundance (from 30-60 individuals per trap-night) and high abundance (more than 
60 individuals per trap-night). This classification was based on previous research showing that higher vector abundance is related to a higher transmission risk of VL (Costa 2008). The maps of Lu. longipalpis abundances recorded from 2007 and 2009 were overlapped. We computed the percentages of areas characterised by a null, low, intermediate or high sandfly abundance according to the categories defined, using the interpolated abundance values obtained from the kriging procedure using ArcView Spatial Analyst 2.0a 2000 (Environmental Systems Research Institute).

Environmental analysis - An environmental analysis was carried out only for the data from 2009 because an analysis of the data from 2007 was previously reported (Fernández et al. 2010). A total of 312 sampled households were included in the analysis to examine the association between $\mathrm{Lu}$. longipalpis and the surveyed environmental characteristics $(90 \%$ of these households were included in the spatial analysis, while the remaining $10 \%$ corresponded to households located outside the grid). Twenty-five environmental characteristics were recorded at each sampling point. The results of the data analysis for 2007 were reviewed to determine the environmental variables to be surveyed for 2009 (Fernández et al. 2010); however, the data analysis for 2007 lacked environmental characteristics surveyed at the microhabitat scale. Despite this lack of available data, the present study incorporated environmental characteristics surveyed within the households at the microhabitat scale. Previous literature was referenced to determine and select microhabitat variables related to the biology of the vector (Gontijo \& Melo 2004, Costa et al. 2005, Lainson \& Rangel 2005, de Oliveira et al. 2006b, Oliveira et al. 2006, Mestre \& Fontes 2007). Additionally, we retained the environmental characteristics that best explained vector abundance in 2007 (Fernández et al. 2010).

Environmental data were obtained from three different sources: (i) land cover classification and cartographic data, (ii) household field characteristics recorded simultaneously with entomological sampling and (iii) Google Earth $^{\mathrm{TM}}$ satellite images (Table I). For land cover classification, we used data provided by the Ente Binacional Yacyretá (EBY). Three different classes of land cover were identified based on an Ikonos remote-sensing image (from April 2009, 1.2-m resolution): herbaceous vegetation, arboreal or shrub vegetation and non-vegetated areas (e.g., streets, roads, paths and buildings). The percentages of these classes were computed with a buffered circular radius of $50 \mathrm{~m}, 100 \mathrm{~m}$ or $200 \mathrm{~m}$ around each sampled household. The distance to the nearest water source (rivers, streams) was computed from a map provided by the EBY. The number of unpaved roads in the block was recorded from the Google Earth ${ }^{\mathrm{TM}}$ satellite images (13 September 2009, $1.62 \mathrm{~km}$ altitude). In these images, the land in the study area appears reddish, while unpaved roads appear red and paved roads appear gray to black.

Twenty characteristics of the households were surveyed simultaneously with the entomological data, related to the vegetation, general conditions and maintenance of the domicile and peridomicile. Finally, three indices were created based on these characteristics: a vegetation index, in which each surveyed vegetation variable contributed to the index, a dwelling index, based on the housing characteristics and the surrounding area, and an animal index, based on the presence of chickens and/ or dogs. Details of the construction of these indices are provided in Table I.

The association between $\mathrm{Lu}$. longipalpis abundance and the examined environmental characteristics was analysed through a forward stepwise multiple regression procedure using generalised linear models (McCullagh $\&$ Nelder 1989). Because the response variable consisted of the number of individuals per trap-night, a Poisson distribution was employed for errors and a logarithm link function was applied. To account for overdispersion, the $\mathrm{SE}$ were corrected using a quasi-Poisson model. Explanatory variables that were significant at the $5 \%$ level were included in the model, establishing parameter estimates/ $\mathrm{SE}$ and degrees of freedom. A two-tailed t test was carried out to determine the significance of the parameter estimates. To avoid multicollinearity between explanatory variables, we discarded those variables that were highly associated with others that had already been included in the model (with $\mathrm{p}<0.01$ for the Pearson correlation test). Following a graphical check of the assumptions of the analysis, one outlier was removed. The parameters were re-sampled using the bootstrap method. The spatial dependence of the sandfly abundance was analysed including an autocovariation matrix in the generalised lineal model, according to the methodology described by Dormann et al. (2007). The autocovariation matrix was computed using the spdep package (Bivand et al. 2013) for R, according to the parameters estimated from the semivariogram function. Then, the autocorrelation of the model residuals was analysed by computing the semivariogram function. All of these analyses were conducted using the R 3.0.0 (R Development Core Team 2013) and S-PLUS 6.0 with a spatial extension module (Insightful 2001).

\section{RESULTS}

In 2007 and 2009, 2,380 (male:female sex ratio of 3.5) and 6,916 (male:female sex ratio of 7.5) Lu. longipalpis were captured, respectively. More than $99 \%$ of the total captures (from 282 and 310 of the sampled houses in 2007 and 2009, respectively) represented this species. During both years, the presence of Evandromyia cortellezzi (2007: 8 individuals, 2009: 11 individuals ) was also recorded and during sampling in 2007, Nyssomyia whitmani and Nyssomyia neivai were observed, each of which was represented by a single captured specimen.

The weather conditions were similar $(p>0.05)$ during the two survey periods according to an independent $\mathrm{t}$ test with the Bonferroni correction: daily maximum temperatures, $32.04^{\circ} \mathrm{C}(2007)$ and $32.96^{\circ} \mathrm{C}(2009)$, daily minimum temperatures, $21.96^{\circ} \mathrm{C}(2007)$ and $22.08^{\circ} \mathrm{C}$ (2009), and daily maximum wind speeds, $28.4 \mathrm{~km} / \mathrm{h}$ (2007) and $30.9 \mathrm{~km} / \mathrm{h}$ (2009).

During both survey periods, Lu. longipalpis was found to be distributed throughout the study area. The percentage of households in which the vector was observed decreased from $41.5-31 \%$ from $2007-2009$, re- 
spectively $(\mathrm{p}=0.008)$. In 2009 , the average recorded abundance was 22.3 individuals per trap-night [SD 93.2 , range $(0: 1,111)]$. This value was almost three times greater than that recorded in 2007 for the same area (8.4 individuals per trap-night, $\mathrm{p}=0.02$ ). In 2009, the spatial autocorrelation of $\mathrm{Lu}$. longipalpis abundance was up to $688 \mathrm{~m}$ (estimated range of the semivariogram function: sill, 8,074; nugget 1,950). This distance was similar to that observed in 2007 (Fernández et al. 2010). The semivariograms created for the four directions indicated isotropy. For both survey periods, sites of intermediate and high abundance of Lu. longipalpis appeared as a pattern of patches within a matrix of low abundance. However, between 2007-2009, some changes were observed in the interpolated abundance in relation to the main patches recorded. From 2007-2009, three patches increased in size: one showed a change in position, three disappeared and six new patches were recorded (Figure).

The estimated areas characterised by null or low vector abundance decreased between the two survey years, from 8.4-6.3\% for null abundance and from $88.6-83 \%$ for low abundance. In contrast, the estimated areas displaying an

\section{TABLE I}

Environmental characteristics analysed to explain the abundance

of Lutzomyia longipalpis in the city of Posadas, Misiones, Argentina, in 2009

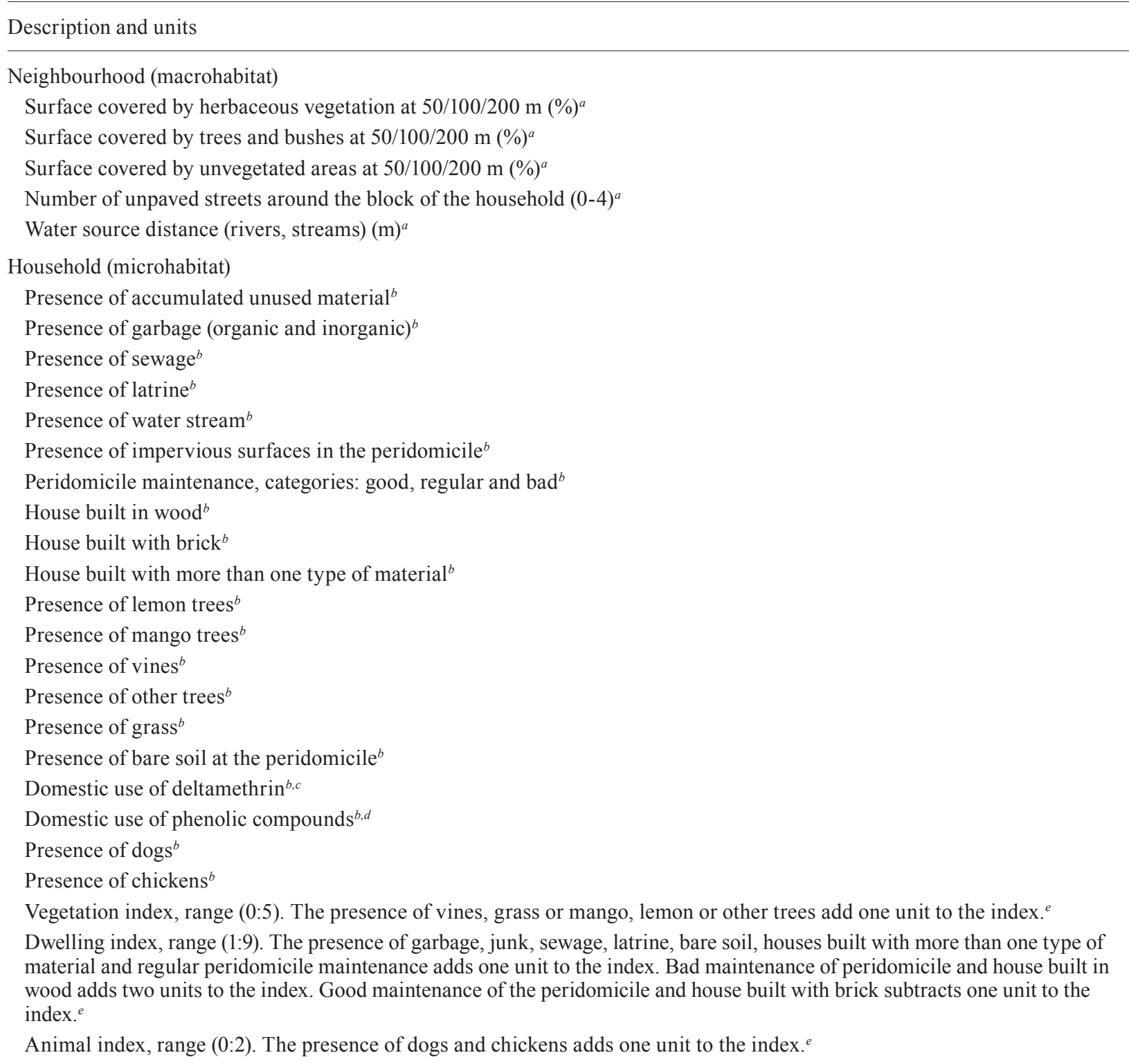

$a$ : land cover classification, cartographic information or Google Earth ${ }^{\mathrm{TM}}$ satellite image; $b$ : field records carried simultaneously with the trapping session; $c$ : K-Othrin $\mathrm{A}^{\circledR} ; d$ : "acaroina"; $e$ : index constructed based on the characteristics surveyed. 
intermediate or high vector abundance increased from 1.6$4.7 \%$ and from $1.4-6.1 \%$ for 2007 and 2009 , respectively.

The abundance of $\mathrm{Lu}$. longipalpis in 2009 was greater at sites with a higher degree of tree or bush cover and an accumulation of unused material in households $(20.25 \%$ of total deviance explained) (Table II). The spatial dependence of the vector abundance was significant in the model $(\mathrm{p}=0.03)$ and the semivariogram created for the residuals of the models showed no spatial dependence. Additionally, the coefficients for the environmental variables did not change substantially by removing the autocovariate term.

\section{DISCUSSION}

Although the pattern of patches was similar between 2007-2009, we observed areas of higher abundance and an overall $265 \%$ increase in the average abundance. It is difficult to know whether this is the first stage of vector colonisation and if vector abundance will continue to increase in the city or if this pattern of abundance will stabilise over time. Despite the focused anti-vector interventions (pyrethroid treatment) carried out by Posadas, the abundance of $L u$. longipalpis increased (OD Salomón and MS Santini, unpublished observations). However, it is not possible to determine the effectiveness of these measures because we cannot predict what the abundance of the vector would have been if these measures had not been taken. In the city of Campo Grande, located in the Central-West Region of Brazil near the study area, the abundance of $\mathrm{Lu}$. longipalpis increased 60 -fold from 1999-2000 to 2004-2005 (de Oliveira et al. 2006a).

From 2007-2009, spatial analysis showed that the areas with an intermediate or high abundance of sandflies increased, whereas the percentage of households with sandflies decreased during this period. These results suggest that vector abundance is likely increasing, but becoming more concentrated in fewer households. It would be worthwhile to study the dispersion of the vector in the following years to confirm this hypothesis.

For both survey years, the SE of the interpolated abundance was higher compared to that of the mean values. These results agree with those reported by Santini et al. (2012), who studied the variance between and within patches. These authors found that the variance in high or low abundances within patches was due to the abundances recorded in the households. Therefore, the higher SE obtained in 2009 in relation to 2007 were likely a result of the higher abundances recorded.

Because the vector is not distributed evenly throughout the city, the observed spatial pattern of $L u$. longi-

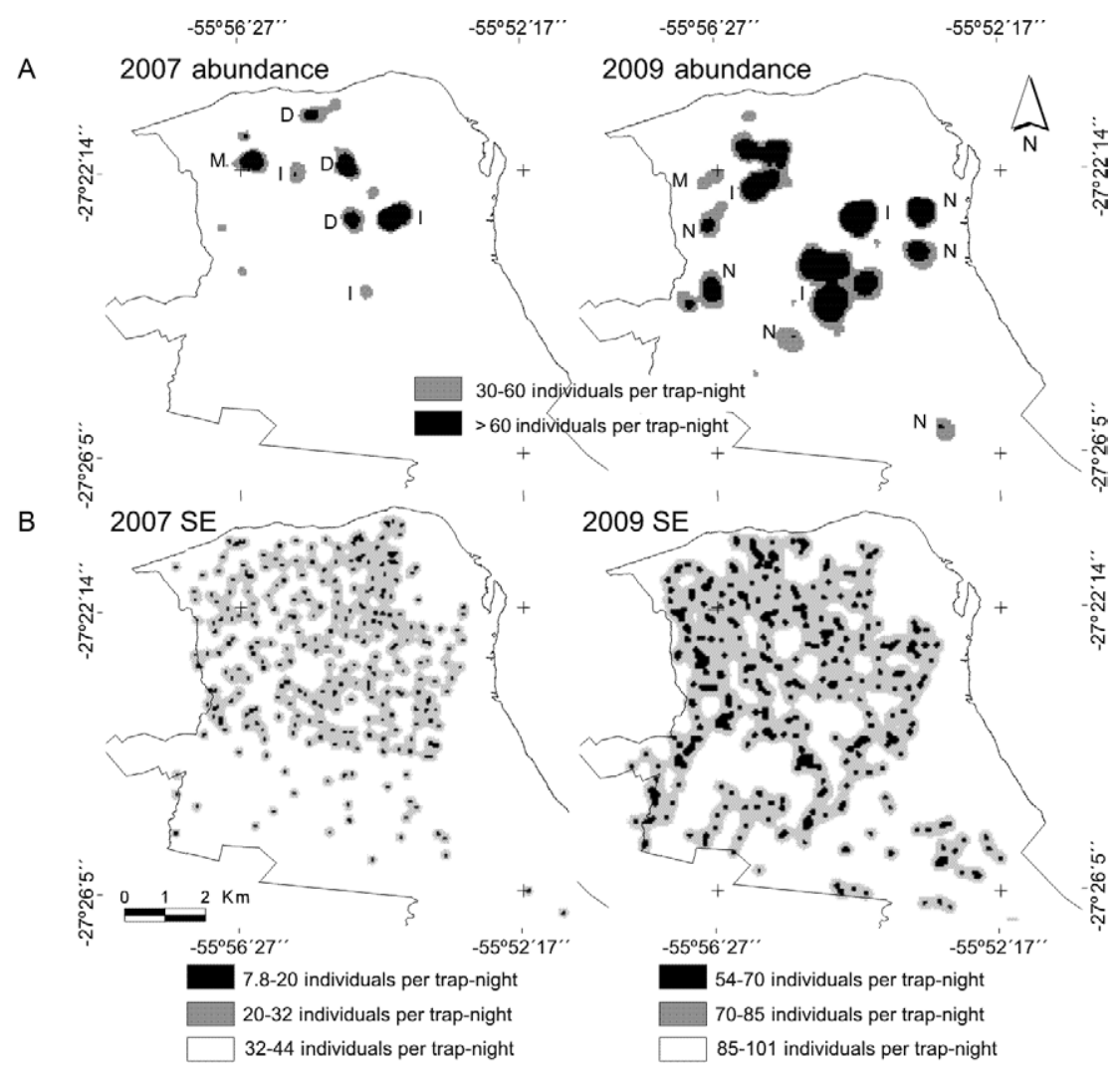

A: interpolated abundance by kriging in summer 2007 and summer 2009 in the city of Posadas, Argentina. The main patches are indicated by capital letters (D: patches that disappeared from 2007-2009; I: patches that increased in size from 2007-2009; M: patches that modified their position in 2009 in relation to their position in 2007; N: new patches that appeared in 2009); B: standard errors (SE) of the kriging procedure for both years (2007 SE and 2009 SE). The year of 2009 showed more variability than 2007 (see reference scale). Note that the colour reference scale of the SE was reversed compared to the vector abundance scale (darker colours mean less error) in order to make the figure more readable. 
palpis abundance has implications for the design and implementation of control measures. The patches with a higher abundance should not be considered completely static over time because, as observed in our data, their size and position in space may change over time and new patches may appear, while others disappear. In this regard, it would be worthwhile to study the effects of changes in biotic and abiotic factors, in addition to human practices. Regular monitoring would be required (though not exclusively, i.e., along with examining other epidemiological criteria, such as active transmission) to improve the efficiency of interventions in patches with high vector abundance. Thus, controlling the vector in these patches of high abundance could have a major impact on parasite transmission in the entire city. By applying the 80/20 principle (Woolhouse et al. 1997), we were able to postulate that effective interventions in areas with a high vector abundance could decrease the transmission of the disease in the city by approximately $80 \%$, taking into consideration the variations and specific characteristics associated with different transmission scenarios.

The similarities between the spatial patterns of the abundance distributions obtained in 2007 and 2009 may reveal characteristics of suitable and unsuitable sites for vector establishment. In this study, we explored the relationship between $L u$. longipalpis abundance and 25 environmental characteristics during 2009. One characteristic that affected the distribution of Lu. longipalpis abundance was the amount of surface area covered by trees and bushes around the household, which is defined as a macrohabitat characteristic. This characteristic explained the greatest deviance in Lu. longipalpis abundance for 2007, within a buffer zone of $50 \mathrm{~m}$; however, all of the examined buffer distances $(50 \mathrm{~m}, 100 \mathrm{~m}$ and $200 \mathrm{~m}$ ) were correlated (Fernández et al. 2010).

In the 2007 survey, only a few characteristics of the households were recorded and the lack of an explanation for the abundance of Lu. longipalpis was partially attributed to this lack of information. Thus, a greater effort was made to describe household characteristics during the 2009 sampling. Although 20 environmental variables were surveyed during household sampling (microhabitat), we did not improve the capacity to explain the distribution of $\mathrm{Lu}$. longipalpis abundance; however, the presence of accumulated unused material within the peridomicile did provide a partial explanation. In the environmental analysis performed in this work, the presence of chickens did not explain the abundance of $L u$. longipalpis. However, in the literature, chickens are described as a risk factor when henhouses are close to human bedrooms, due to an increase in the attractiveness and availability of potential breeding sites (Alexander et al. 2002, Dias et al. 2003, Oliveira et al. 2003, Missawa et al. 2008). An association between chickens and intermediate or high vector abundances has been previously reported (Fernández et al. 2010). In the present study, chickens were recorded in the peridomicile, in close association with humans.

Although we found no evidence of dogs acting as a risk factor for vector abundance, they were present in $60 \%$ of the households sampled. In the same study area, Santini et al. (2010) found that dogs must remain at a distance of $5 \mathrm{~m}$ to prevent the insect from landing in humans, thus demonstrating the importance of keeping dogs away from the humans.

Based on the present study and previous findings (Fernández et al. 2010, Santini et al. 2012), tree and shrub cover would be an environmental characteristic that is related to sandfly abundance. However, further studies will be needed to determine whether sandfly abundance is associated with certain tree species with particular characteristics (e.g., deciduous trees). Within high-abundance patches, the presence of accumulated unused material in the peridomicile may provide suitable conditions (e.g., shelter and shade) for the vector.

Our results agree with those obtained by de Oliveira et al. (2012) in the state of Mato Grosso do Sul, Brazil. These authors found an association between $\mathrm{Lu}$. longipalpis and the vegetation cover, thus concluding that large trees may offer a better microenvironment where sandflies can find appropriate refuge and breeding sites. They also observed a greater vector abundance in households with chickens. Therefore, the authors suggested that sandfly populations are concentrated in small areas where the food supply is satisfactory, coinciding with the presence of large vegetation covering. Defining variables that might be related to vector biology is often a difficult task, especially in an urban context, where the number

\section{TABLE II}

Multiple regression model, general linear model [parameter estimates and standard errors (SE)] for the abundance of Lutzomyia longipalpis as a function of environmental and demographic variables in the city of Posadas, Misiones, Argentina, in 2009

\begin{tabular}{|c|c|c|c|c|}
\hline Variable & $\begin{array}{l}\text { Parameter } \\
\text { estimates }\end{array}$ & SE & $\mathrm{p}$ & $\begin{array}{l}\text { Habitat scale } \\
\text { interpretation }\end{array}$ \\
\hline Intercept & -0.911 & 1.147 & 0.427 & - \\
\hline Presence of accumulated unused material & 1.610 & 0.320 & $<0.001$ & Micro \\
\hline Proportion covered by trees and bushes $100 \mathrm{~m}$ around the sampling point & 7.457 & 2.634 & 0.004 & Macro \\
\hline Autocovariate & 0.008 & 0.004 & 0.031 & - \\
\hline
\end{tabular}

null deviance $=26175.19$, degrees of freedom $(\mathrm{df})=310$; residual deviance $=20876, \mathrm{df}=307$. 
of possible variables (biological and sociodemographic) is large. The preliminary results presented here provide a framework of variables to be considered and built upon in future studies of Leishmania vectors in urban environments. The environmental models created for Posadas may be used as a starting point when creating more-robust predictive models of $\mathrm{Lu}$. longipalpis abundance, specifically for selecting appropriate environmental characteristics in an urban environment. The consistency of some of the environmental indicators in the models constructed for 2007 and 2009 suggests that these variables should be considered in future studies. Other factors that were not considered in this analysis, such as microclimatic variables, could also improve the model.

Finally, if the patches of high vector abundance observed in Posadas can be used to establish a general pattern for urban environments, it could contribute to explaining the clustering patterns found in the transmission of human and canine VL (Waleska et al. 2005, Carneiro et al. 2007). Margonari et al. (2006) observed that, in general, sites with a high abundance of sandflies correspond to many human and canine cases of VL. Therefore, a risk map for VL transmission based on $L u$. longipalpis abundances and canine VL could be built and used to prevent human cases. A robust environmental model will enable the estimation of vector abundance and the incorporation of this information directly into the construction of risk maps.

\section{ACKNOWLEDGEMENTS}

To Dr Lilian Tartaglino, Secretary of Quality of Life of Posadas, and members of the Vector Laboratory, for the support, logistics and interest to redeem the problems of the region, to the Environment Sector and Appraisal Commission of EBY, for the cartography, the satellite imaginary and the supervised classification processing of the sample sites, and to María Eugenia Utgés, for reviewing this paper.

\section{REFERENCES}

Alexander B, de Carvalho RL, McCallum H, Pereira MH 2002. Role of the domestic chicken (Gallus gallus) in the epidemiology of urban visceral leishmaniasis in Brazil. Emerg Infect Dis 8: 1480-1485.

Antonialli SAC, Torres TG, Paranhos Filho AC, Tolezano JE 2007. Spatial analysis of American visceral leishmaniasis in Mato Grosso do Sul state, Central Brazil. J Infect 54: 509-514.

Bivand R, Altman M, Anselin L, Assunasaeo R, Berke O, Bernat A, Blanchet G, Blankmeyer E, Carvalho M, Christensen B, Chun Y, Dormann C, Dray S, Halbersma R, Krainski E, Legendre P, Lewin-Koh N, Li H, Ma J, Millo G, Mueller W, Ono H, PeresNeto P, Piras G, Reder M, Tiefelsdorf M, Yu D 2013. Spdep: spatial dependence: weighting schemes, statistics and models. R package version 0.5-56. Available from: CRAN.R-project.org/ package $=$ spdep.

Carneiro DMT, Bavia ME, Rocha WJ, Tavares ACQ, Cardim LL, Alemayehu B 2007. Application of spatio-temporal scan statistics for the detection of areas with increased risk for American visceral leishmaniasis in the state of Bahia, Brazil. Geospat Health 2: 113-126.

Cerbino Neto J, Werneck GL, Costa CHN 2009. Factors associated with the incidence of urban visceral leishmaniasis: an ecological study in Teresina, Piauí state, Brazil. Cad Saude Publica 25: 1543-1551.
Costa $\mathrm{CH}$ 2008. Characterization and speculations on the urbanization of visceral leishmaniasis in Brazil. J Med Entomol 47: 972-976.

Costa CH, Werneck GL, Rodrigues Jr L, Santos MV, Araújo IB, Moura LS, Moreira S, Gomes RB, Lima SS 2005. Household structure and urban services: neglected targets in the control of visceral leishmaniasis. Ann Trop Med Parasitol 99: 229-236.

de Oliveira AG, Galati EAB, de Oliveira O, de Oliveira GR, Espindola IAC, Dorval MEC, Brazil RP 2006a. Abundance of Lutzomyia longipalpis (Diptera: Psychodidae: Phlebotominae) and urban transmission of visceral leishmaniasis in Campo Grande, state of Mato Grosso do Sul, Brazil. Mem Inst Oswaldo Cruz 101: 869-874.

de Oliveira ALL, Paniago AMM, Dorval MEC, Oshiro ET, Leal CR, Sanches M, da Cunha RV, Bóia MN 2006b. Foco emergente de leishmaniose visceral em Mato Grosso do Sul. Rev Soc Bras Med Trop 39: 446-450.

de Oliveira EF, Silva EA, Fernandes CES, Paranhos Filho AC, Gamarra RM, Ribeiro AA, Brazil RP, de Oliveira AG 2012. Biotic factors and occurrence of Lutzomyia longipalpis in endemic area of visceral leishmaniasis, Mato Grosso do Sul, Brazil. Mem Inst Oswaldo Cruz 107: 396-401.

Dias FO, Lorosa ES, Rebêlo JM 2003. Fonte alimentar sanguínea e a peridomiciliação de Lutzomyia longipalpis (Lutz \& Neiva, 1912) (Psychodidae, Phlebotominae). Cad Saude Publica 19: 1373-1380.

Dormann CF, McPherson JM, Araujo MB, Bivand R, Bolliger J, Carl G, Davies RG, Hirzel A, Jetz W, Kissling WD, Kuhn I, Ohlemuller R, Peres-Neto PR, Reineking B, Schroder B, Schurr FM, Wilson R 2007. Methods to account for spatial autocorrelation in the analysis of species distributional data: a review. Ecography 30: 609-628.

Feliciangeli MD, Delgado O, Suarez B, Bravo A 2006. Leishmania and sand flies: proximity to woodland as a risk factor for infection in a rural focus of visceral leishmaniasis in west central Venezuela. Trop Med Int Health 11: 1785-1791.

Fernández MS, Lestani EA, Cavia R, Salomón OD 2012. Phlebotominae fauna in a recent deforested area with American tegumentary leishmaniasis transmission (Puerto Iguazú, Misiones, Argentina): seasonal distribution in domestic and peridomestic environments. Acta Trop 122: 16-23.

Fernández MS, Salomón OD, Cavia R, Pérez AA, Acardi SA, Guccione JD 2010. Lutzomyia longipalpis spatial distribution and association with environmental variables in an urban focus of visceral leishmaniasis, Misiones, Argentina. Acta Trop 114: 81-87.

Galati EAB 2003. Morfologia, terminologia de adultos e identificação dos táxons da América. In EF Rangel, R Lainson, Flebotomíneos do Brasil, Fiocruz, Rio de Janeiro, p. 53-175.

Gontijo CMF, Melo MNM 2004. Leishmaniose visceral no Brasil: quadro atual, desafios e perspectivas. Rev Bras Epidemiol 7: 338-349.

Harhay MO, Olliaro PL, Costa DL, Costa CH 2011. Urban parasitology: visceral leishmaniasis in Brazil. Trends Parasitol 7: 403-409.

Insightful C 2001. S-PLUS (version 6.0 Professional), Seattle, USA.

Lainson R, Rangel EF 2005. Lutzomyia longipalpis and the eco-epidemiology of American visceral leishmaniasis, with particular reference to Brazil - A Review. Mem Inst Oswaldo Cruz 100: 811-827.

Marcondes CB 2007. A proposal of generic and subgeneric abbreviations for phlebotomine sandflies (Diptera: Psychodidae: Phlebotominae) of the word. Entomol News 118: 351-356.

Margonari C, Freitas CR, Ribeiro RC, Moura ACM, Timbó M, Gripp AH, Pessanha JE, Dias ES 2006. Epidemiology of visceral leish- 
maniasis through spatial analysis, in Belo Horizonte municipality, state of Minas Gerais, Brazil. Mem Inst Oswaldo Cruz 101: 31-38.

McCullagh P, Nelder JA 1989. Generalized linear models, 2nd ed., Chapman \& Hall/CRC, Boca Raton, 532 pp.

Mestre GLC, Fontes CJF 2007. A expansão da epidemia da leishmaniose visceral no estado de Mato Grosso, 1998-2005. Rev Soc Bras Med Trop 40: 42-48.

Missawa NA, Lorosa ES, Dias ES 2008. Preferência alimentar de Lutzomyia longipalpis (Lutz \& Neiva, 1912) em área de transmissão de leishmaniose visceral em Mato Grosso. Rev Soc Bras Med Trop 41: 365-368.

Morris DW 1987. Ecological scale and habitat use. Ecology 68: $362-$ 369.

Oliveira AG, Andrade Filho JD, Falcão AL, Brazil RP 2003. Estudo de flebotomíneos (Diptera, Psychodidae, Phlebotominae) na zona urbana da cidade de Campo Grande, Mato Grosso do Sul, Brasil, 1999-2000. Cad Saude Publica 19: 933-944.

Oliveira AG, Galati EAB, Fernandes CE, Dorval MEC, Brazil RP 2008. Seasonal variation of Lutzomyia longipalpis (Lutz \& Neiva, 1912) (Diptera: Psychodidae: Phlebotominae) in endemic area of visceral leishmaniasis, Campo Grande, state of Mato Grosso do Sul, Brazil. Acta Trop 105: 55-61.

Oliveira CD, Diez-Roux A, César CC, Proietti FA 2006. A case-control study of microenvironmental risk factors for urban visceral leishmaniasis in a large city in Brazil, 1999-2000. Rev Panam Salud Publica 20: 369-376.

R Development Core Team 2013. R: a language and environment for statistical computing. Available from: R-project.org.
Ready PD 2008. Leishmaniasis emergence and climate change. Rev Sci Tech 27: 399-412.

Salomón OD, Quintana MG 2011. Leishmaniasis y ambiente: uso de sensores remotos y sistemas de información geográfica. In J Basualdo, R Cacchione, R Durlach, P Martino, A Seijo (eds.), Temas de zoonosis V, Asociación Argentina de Zoonosis, Buenos Aires, p. $175-188$.

Salomón OD, Sinagra A, Nevot MC, Barberian G, Paulin P, Estevez JO, Riarte A, Estevez J 2008. First visceral leishmaniasis focus in Argentina. Mem Inst Oswaldo Cruz 103: 109-111.

Santini MS, Fernández MS, Pérez AA, Sandoval AE, Salomón OD 2012. Lutzomyia longipalpis abundance in the city of Posadas, northeastern Argentina: variations at different spatial scales. Mem Inst Oswaldo Cruz 107: 767-771.

Santini MS, Salomón OD, Acardi SA, Sandoval EA, Tartaglino L 2010. Lutzomyia Longipalpis behavior and control at an urban visceral leishmaniasis focus in Argentina. Rev Inst Med Trop Sao Paulo 52: 187-191.

Sherlock IA 1996. Ecological interactions of visceral leishmaniasis in the state of Bahia, Brazil. Mem Inst Oswaldo Cruz 91: 671-683.

Waleska TC, Almeida MCM, Oliveira CL, Friche AAL, Matos SG, Dias MAS, Cunha MCM, Pessanha E, Proietti FA 2005. The urban environment from the health perspective: the case of Belo Horizonte, Minas Gerais, Brazil. Cad Saude Publica 21: 958-967.

Woolhouse ME, Dye C, Etard JF, Smith T, Charlwood JD, Garnett GP, Hagan P, Ndhlovu P, Quinnell RJ, Watts CH, Chandiwana SK, Anderson RM 1997. Heterogeneities in the transmission of infectious agents: implications for the design of control programs. Proc Natl Acad Sci USA 94: 338-342. 